\title{
Personalisation of Therapies in COVID-19 Associated Acute Respiratory Distress Syndrome, Using Electrical Impedance Tomography
}

\author{
Atsuko Shono ${ }^{1}$, Toru Kotani ${ }^{1 *}$, Inéz Frerichs ${ }^{2}$ \\ 1 Department of Intensive Care Medicine, Showa University School of Medicine, Shinagawa, Tokyo Japan \\ 2 Department of Anesthesiology and Intensive Care Medicine, University Medical Center, Schleswig-Holstein, Campus \\ Kiel, Germany
}

\begin{abstract}
Introduction: Each patient suffering from severe coronavirus COVID-19-associated acute respiratory distress syndrome (ARDS), requiring mechanical ventilation, shows different lung mechanics and disease evolution. Therefore, lung protective strategies should be personalised for the individual patient. Case presentation: A 64-year-old male patient was intubated ten days after the symptoms of COVID-19 infection presented. He was placed in the prone position for sixteen hours, resulting in a marked improvement in oxygenation. However, after being returned to the supine position, his $\mathrm{SpO}_{2}$ rapidly dropped from $98 \%$ to $91 \%$, and electrical impedance tomography showed less ventilation at the dorsal region and a ventral shift of ventilation distribution. An incremental and decremental PEEP trial under electrical impedance tomography monitoring was carried out, confirming that the dependent lung regions were recruited with increased pressures and homogenous ventilation distribution could be provided with $14 \mathrm{cmH}_{2} \mathrm{O}$ of PEEP. The optimal settings were reassessed next day after returning from the second session of the prone position. After four prone position-sessions in five days, oxygenation was stabilised and eventually the patient was discharged. Conclusions: Patients with COVID-19 associated ARDS require individualised ventilation support depending on the stage of their disease. Daily PEEP trial monitored by electrical impedance tomography can provide important information to tailor the respiratory therapies.
\end{abstract}

Keywords: coronavirus infection, pneumonia, respiratory distress syndrome, positive-pressure respiration, electrical impedance tomography, prone position sessions

Received: 19 July 2020 / Accepted: 24 November 2020

\section{INTRODUCTION}

The coronavirus disease 2019 (COVID-19) has emerged as a cause of acute respiratory failure worldwide. Due to hypoxemia, patients are intubated and placed on mechanical ventilation at an early stage in the course of treatment.

Once patients are intubated, the current recommendations are to follow the concept and strategies suggested for the management of acute respiratory distress syndrome (ARDS).

Different lung mechanics and disease evolution make patient management difficult when COVID-19 pneumonia presents with concomitant respiratory failure. Consequently, the recommended strategies, including prone positioning, are not always suitable for all patients and should be personalised for each patient daily.

Electrical impedance tomography is a monitoring tool that can visualise changes in ventilation and aeration caused by therapeutic interventions such as changes in body position, ventilatory settings, administration of muscle relaxant, and weaning [1-4].

The case of a mechanically ventilated patient with COVID-19 associated ARDS is described, in which better ventilatory settings are investigated by applying incremental and decremental positive end-expiratory 
pressure (PEEP) trials using electrical impedance tomography, after returning to the supine position from the prone position.

\section{CASE PRESENTATION}

The patient was a 64-year-old man diagnosed previously as having diabetes mellitus, with a body mass index 28. He had developed cough, fever, and dyspnea ten days before his admission to the Department of Internal Medicine, General Hospital, Tokyo, Japan.

Throat swab specimens were taken on admission to this hospital and analysed using polymerase chain reaction for SARS-CoV-2, which tested positive. The patient was intubated immediately on admission due to hypoxia and was transferred the day after admission, from the peripheral hospital to a University Hospital in Tokyo, Japan. Upon admission to this hospital, he was deeply sedated and paralysed due to the continuous infusion of 1\% Propofol Intravenous Solution (Maruishi Pharmaceuticals, Osaka, Japan), and Rocuronium Bromide Intravenous Solution ${ }^{\oplus}$, (Maruishi Pharmaceuticals, Osaka, Japan) given by the previous hospital.

Laboratory tests showed C-reactive protein $8.3 \mathrm{mg} /$ $\mathrm{dl}$, ferritin $2806 \mathrm{ng} / \mathrm{dl}$, and D-dimer $10.7 \mu \mathrm{g} / \mathrm{ml}$. A chest computed tomography (CT) taken on admission, showed ground-glass opacity accompanied by consolidation at both dorsal lung regions (Fig. 1)

The patient was managed with pressure-controlled ventilation with a PEEP of $10 \mathrm{cmH}_{2} \mathrm{O}$ and an inspiratory pressure of $24 \mathrm{cmH}_{2} \mathrm{O}$. The tidal volume was $450 \mathrm{ml}$, $6.4 \mathrm{ml} / \mathrm{kg} /$ predicted body weight, and arterial partial

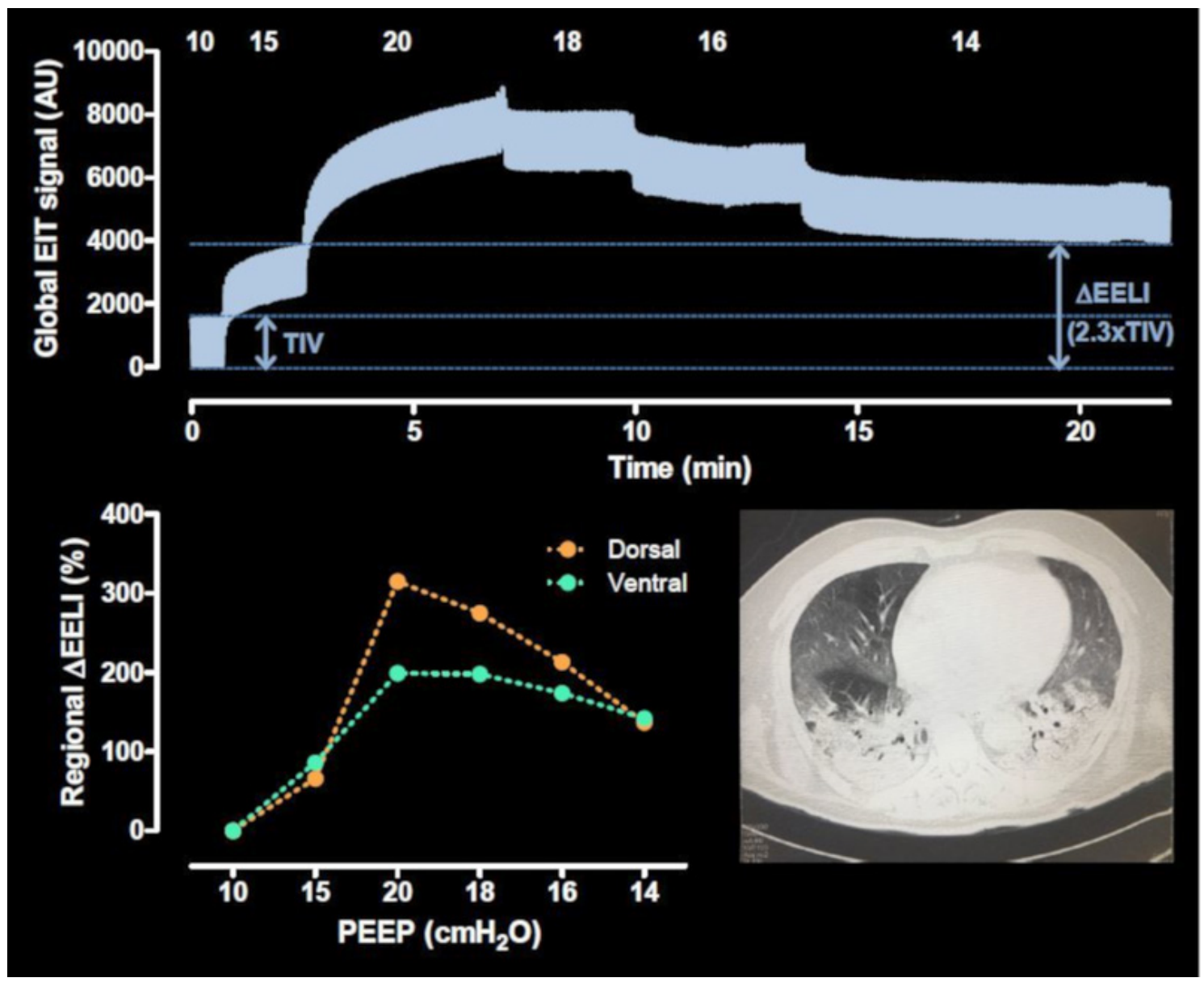

Fig. 1. A Global EIT signal waveform in arbitrary units (AU) acquired in a supine patient suffering from COVID-19 related ARDS during two incremental and four decremental steps in positive end-expiratory pressure (PEEP) (top). The blue arrows show the amplitude of tidal impedance variation (TIV) during ventilation at the initial PEEP value and the change in end-expiratory lung impedance at the last PEEP value compared to the beginning of the manoeuvre. The numbers above the waveform present the set PEEP values in $\mathrm{cmH}_{2} \mathrm{O}$. Regional $\Delta$ end-expiratory lung impedance in ventral and dorsal lung regions relative to the initial values at the lowest PEEP (bottom left) demonstrate the more pronounced increase in the dependent regions, implying recruitment. Chest CT scan (bottom right) was obtained on Day 1 of ICU admission. 
pressure of oxygen $\left(\mathrm{PaO}_{2}\right) /$ fraction of inspired oxygen $\left(\mathrm{FIO}_{2}\right)$ was $142 \mathrm{mmHg}$.

He was placed in the prone position for 16 hours, which resulted in better oxygenation when a $\mathrm{PaO}_{2} /$ $\mathrm{FIO}_{2}$ of $259 \mathrm{mmHg}$ was recorded.

On the morning of Day 2, post-admission to the intensive care unit, after being returned to the supine position, and without changing the ventilatory settings, his $\mathrm{SpO}_{2}$ rapidly dropped from $98 \%$ to $91 \%$.

Real-time monitoring by electrical impedance tomography (PulmoVista 500, Draegerwerk, Luebeck, Germany) showed reduced ventilation at the dorsal region and a ventral shift of ventilation distribution.

Therefore, an incremental PEEP trial was performed with a step of $5 \mathrm{cmH}_{2} \mathrm{O}$ from 10 to $20 \mathrm{cmH}_{2} \mathrm{O}$ using a driving pressure of $15 \mathrm{cmH}_{2} \mathrm{O}$. Constant attention was paid to the possible deterioration of the patient's hemodynamics.

The dynamic images at $20 \mathrm{cmH}_{2} \mathrm{O}$ of PEEP showed an increased dorsal ventilation distribution and simultaneous loss of ventral ventilation distribution, indicat- ing that the lungs had responded well to an increased inspiratory pressure (Fig. 2).

The PEEP was lowered, with a step of $2 \mathrm{cmH}_{2} \mathrm{O}$, from $20 \mathrm{cmH}_{2} \mathrm{O}$ until the lungs could be ventilated evenly (Fig. 2), and the PEEP level of $14 \mathrm{cmH}_{2} \mathrm{O}$ was sufficient to maintain the dorsal ventilation. At this level, the increase in end-expiratory lung impedance was twice as much as the tidal impedance variation at the initial PEEP setting of $10 \mathrm{cmH}_{2} \mathrm{O}$ (Fig. 1). These results signified that the end-expiratory lung volume increased twice as much as the tidal volume of PEEP at ten $\mathrm{cmH}_{2} \mathrm{O}$.

The increase in end-expiratory lung impedance was more pronounced in the dorsal than in the ventral region (Fig. 1 bottom left). The combination of increased end-expiratory lung impedance and ventilation distribution in the dorsal region indicated the recruitment of a previously collapsed lung area.

Although $\mathrm{SpO}_{2}$ did not return to the levels obtained when the patient was in the prone position, it was sustained above $94 \%$. A $14 \mathrm{cmH}_{2} \mathrm{O}$ of PEEP was selected

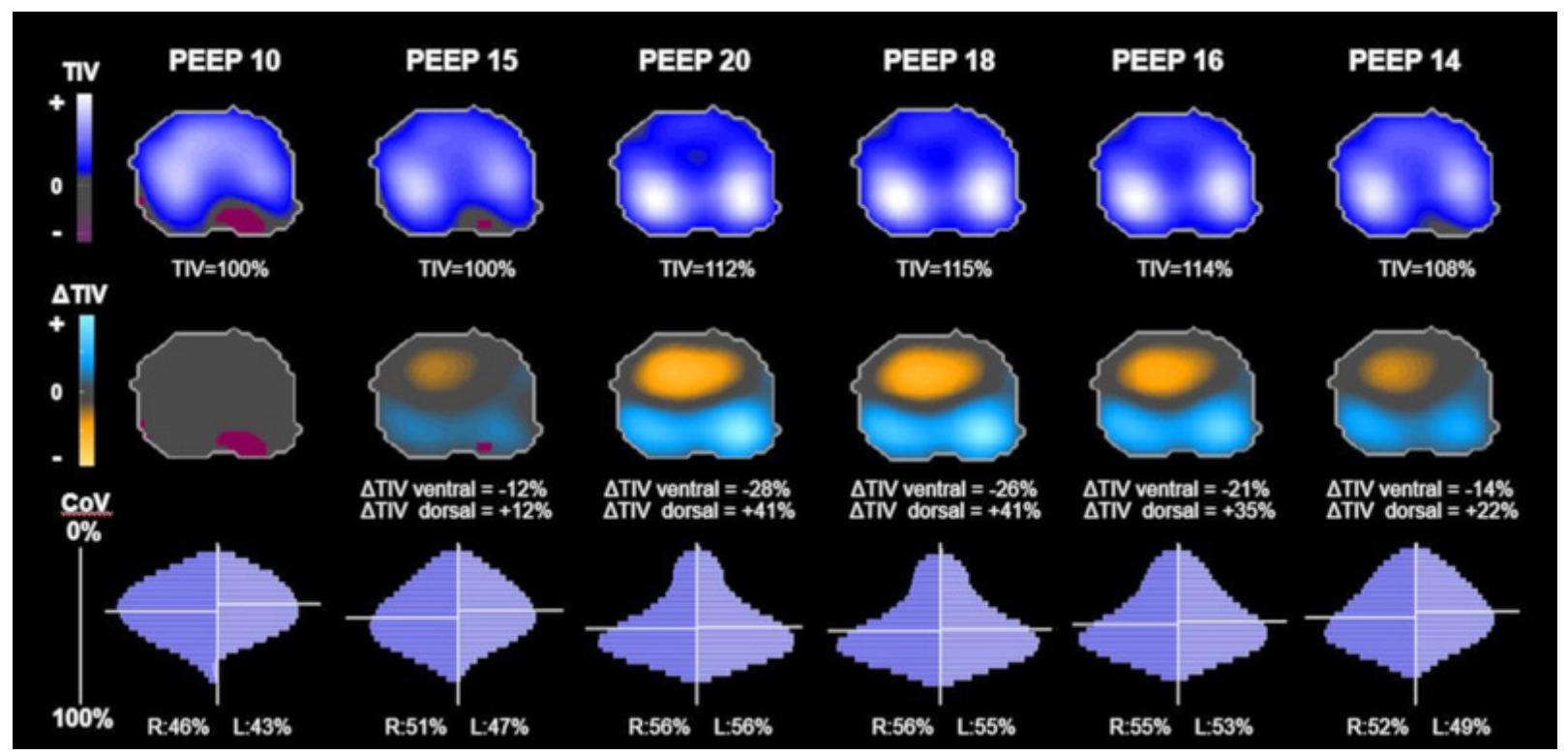

Fig. 2. The figure shows the analysis of regional lung ventilation in a supine patient with COVID-19 related ARDS using EIT, carried out during two incremental and four decremental steps in positive end-expiratory pressure (PEEP). Functional EIT images of regional tidal impedance variation (TIV) (top) show the distribution of tidal volume in the chest cross-section. Ventilated areas are presented in white and blue colors, the numbers below the images give the global sums of TIV values in percent of initial value at PEEP of $10 \mathrm{cmH}_{2} \mathrm{O}$. Functional EIT images of regional changes in TIV $(\Delta T I V)$ (middle) highlight the local increases (light blue areas) and decreases (orange areas) in ventilation at individual PEEP values in comparison with the initial lowest PEEP. The numbers below the images specify the relative changes in TIV in ventral and dorsal lung regions in comparison with the initial TIV distribution at the start of the manoeuvre. Ventilation profiles (bottom) show the distribution of ventilation in the right and left lung regions along the ventrodorsal chest diameter. White horizontal lines in each profile indicate the location of the centre of ventilation (CoV) with the corresponding values plotted below each profile. Values smaller than $50 \%$ imply preferential ventilation distribution towards ventral regions. 
as an appropriate level and an inspiratory pressure of $28 \mathrm{cmH}_{2} \mathrm{O}$, allowed the maintenance of a tidal volume of 6-7 $\mathrm{ml} / \mathrm{kg} /$ predicted body weight.

On Day 2, post-admission to the ICU, the patient was placed in the prone position for sixteen hours without a change in the ventilatory settings.

On Day 3, after the patient was returned to the supine position, the $\mathrm{SpO}_{2}$ did not decrease. A PEEP trial was performed once more to confirm the unchanged appropriate PEEP level, which was recorded as $15 \mathrm{~cm}$ $\mathrm{H}_{2} \mathrm{O}$ of PEEP.

On Day 5 post-admission to the ICU, the more homogeneous distribution of ventilation was maintained by a previously selected inspiratory pressure of $28 \mathrm{~cm}$ $\mathrm{H}_{2} \mathrm{O}$ and $\mathrm{PEEP}$ of $15 \mathrm{cmH}_{2} \mathrm{O}$.

Though a further increase in $\mathrm{PaO}_{2} / \mathrm{FIO}_{2}$ was not achieved, oxygenation was eventually stabilised after four prone positioning sessions in five days. The ventilatory mode was switched to pressure support mode on ICU Day 6.

The maximum levels of laboratory tests during ICU stay were C-reactive protein $22 \mathrm{mg} / \mathrm{dl}$, ferritin $3541 \mathrm{ng} /$ $\mathrm{dl}$, and D-dimer $37.5 \mu \mathrm{g} / \mathrm{ml}$.

Two days later, on ICU Day 8, the patient was transferred to the peripheral hospital, where he showed further improvement.

\section{DISCUSSION}

In COVID-19 associated pneumonia, it was demonstrated that hypoxemia was associated with pronounced elevation of inflammatory markers and inhospital mortality [5].

The causes of hypoxemia are suggested as a ventilation to perfusion (V/Q) mismatch due to the dysfunction of pulmonary vasoconstriction, the presence of micro and macro-thrombosis of the pulmonary vessels increasing dead space, and global or regional change of respiratory system mechanics $[6,7]$.

Hypercoagulability and myocardial damage could represent a causative pattern of macro-thrombosis in COVID-19. Moreover, the hypothesis that right heart thrombosis (RiHTh) could represent an emerging complication in COVID-19 patients deserves the utmost attention given the high associated mortality [8].

In the present case, deep sedation during transportation accelerated the dorsal atelectasis. The prone positioning was chosen to avoid severe hypoxemia on
ICU Day 1. This manoeuvre resulted in improved oxygenation, which, however, returned to previous levels immediately on the patient being returned to the supine position. This indicated that changes might follow improved oxygenation during the prone positioning in the distribution of pulmonary perfusion leading to decrease in V/Q mismatch, and not necessarily by homogenising regional ventilation.

Allowing the dorsal parts of the lungs to remain collapsed might result in an instantaneous fall in oxygenation in the supine position. This speculation was confirmed by the initial evaluation of electrical impedance tomography, which showed the dorsal-area collapse (Fig. 2).

Improving inhomogeneous ventilation plays a role, especially in patients with consolidated lungs. In fact, by focusing on maintaining homogeneous ventilation, the patient did not exhibit further deterioration in oxygenation until discharge. On the other hand, mild impairment of oxygenation persisted during his ICU stay, which might have been caused by other pathomechanisms. An elevated level of D-dimer might imply the presence of micro-thrombosis, leading to persistent impairment of microcirculation [9].

Recent reports demonstrated that an impairment in gas exchange and lung mechanics in COVID-19 associated ARDS is comparable to prior cohorts of nonCOVID-19 associated ARDS [10-13].

Though it varies at different stages of disease course, low respiratory compliance in COVID-19 associated ARDS patients is not rare. In COVID-19 associated ARDS, the lungs are small with limited well-aerated areas, as presented CT image in our case.

In such a cohort, lung protective strategies are recommended. Because of a rapid change of pathophysiology and unsuitableness of frequent transportation of COVID-19 associated ARDS patient, a monitoring tool, available at the bedside, is necessary to allow prompt judgment and decisions, and the implementation of the right timing of changes to the treatment strategy.

Electrical impedance tomography monitoring can meet this requirement by evaluating the lung recruitability through repeated PEEP trials and subsequent PEEP selection [14-16]. The risk of over-distention of the lung tissue is another concern.

In our case, it was confirmed that the nondependent ventral-lung region was receiving less inspired gas but was still ventilated with an inspiratory pressure of 34 
$\mathrm{cmH}_{2} \mathrm{O}$, suggesting no over-distension (Fig. 2). On the other hand, the end-expiratory lung impedance and the dorsal distribution of ventilation had already increased at this pressure level, indicating that the dorsal part of the collapsed lungs was recruited successfully.

\section{- CONCLUSIONS}

Patients suffering from severe COVID-19 associated $A R D S$ require individualised ventilation support depending on the stage of their disease. Electrical impedance tomography helps detect the disease state at the bedside and allows any respiratory therapies to be tailored to the individual patient's needs.

\section{CONFLICT OF INTEREST}

None to declare.

\section{DEFERENCES}

1. Frerichs I, Amato MBP, van Kaam AH, et al. Chest electrical impedance tomography examination, data analysis, terminology, clinical use and recommendations: consensus statement of the TRanslational EIT developmeNt stuDy group. Thorax. 2016;72:83-93.

2. Ukere A, März A, Wodack KH, et al. Perioperative assessment of regional ventilation during changing body positions and ventilation conditions by electrical impedance tomography. $\mathrm{Br}$ J Anaesth. 2016; 117:228-35.

3. Shono A, Kotani T. Clinical implication of monitoring regional ventilation using electrical impedance tomography. J Intensive Care. 2019;7:4.

4. Zhao Z, Peng SY, Chang MY, et al. Spontaneous breathing trials after prolonged mechanical ventilation monitored by electrical impedance tomography: an observational study. Acta Anaesthesiol Scan. 2017; 61:1166-1175.

5. Xie J, Covassin N, Fan Z, et al. Association Between Hypoxemia and Mortality in Patients With COVID-19. Mayo Clin Proc.
2020;95:1138-114.

6. Marini J, Gattinoni L: Management of COVID-19 Respiratory Distress. JAMA. 2020;323:2329-2330.

7. Carsana L, Sonzogni A, Nasr A, et al. Pulmonary post-mortem findings in a series of COVID-19 cases from northern Italy: a two-centre descriptive study. Lancet Infect Dis. 2020. DOI: 10.1016/S1473-3099(20)30434-5.

8. Martelli G,et al. , 2020. JCCM , DOI: 10.2478/jccm-20200039. [ahead of print]

9. Helms J, Tacquard C, Severac F, et al. High risk of thrombosis in patients with severe SARS-CoV-2 infection: a multicenter prospective cohort study. Intensive Care Med. Intensive Care Med. 2020;46:1089-1098. \&\&

10. Barbeta E, Motos A, Torres A, et al. SARS-CoV-2-induced Acute Respiratory Distress Syndrome: Pulmonary Mechanics and Gas Exchange Abnormalities. Ann Am Thorac Soc. 2020. DOI: 10.1513/AnnalsATS.202005-462RL.

11. Bhatraju PK, Ghassemieh BJ, Nichols M, et al. Covid-19 in Critically III Patients in the Seattle Region- Case Series. N Engl J Med. 2020; DOI: 10.1056/NEJMoa2004500

12. Guérin C, Reignier J, Richard JC, et al. Prone positioning in severe acute respiratory distress syndrome. N Engl J Med. 2013;368:2159-68.

13. Bellani G, Laffey JG, Pham T, et al. Epidemiology, Patterns of Care, and Mortality for Patients With Acute Respiratory Distress Syndrome in Intensive Care Units in 50 Countries. JAMA. 2016; 315:788-800.

14. Fumagalli J1, Santiago RRS, Teggia Droghi M, et al. Lung Rescue Team Investigators: Lung Recruitment in Obese Patients with Acute Respiratory Distress Syndrome. Anesthesiology. 2019;130:791-803.

15. Nestler C, Simon P, Petroff D, et al. Individualised positive end-expiratory pressure in obese patients during general anaesthesia: a randomised controlled clinical trial using electrical impedance tomography. $\mathrm{Br} J$ Anaesth. 2017;119:1194-1205.

16. Spadaro S, Mauri T, Böhm SH, et al. Variation of poorly ventilated lung units (silent spaces) measured by electrical impedance tomography to dynamically assess recruitment. Crit Care. 2018;22:26. 